\title{
The Fragmented Evolution of Racial Integration since the Civil Rights Movement
}

\author{
Michael D. M. Bader, ${ }^{\text {a Siri Warkentien }}{ }^{\text {b }}$
}

a) American University; b) Johns Hopkins University

Abstract: We argue that existing studies underestimate the degree to which racial change leads to residential segregation in post-Civil Rights American neighborhoods. This is because previous studies only measure the presence of racial groups in neighborhoods, not the degree of integration among those groups. As a result, those studies do not detect gradual racial succession that ends in racially segregated neighborhoods. We demonstrate how a new approach based on growth mixture models can be used to identify patterns of racial change that distinguish between durable integration and gradual racial succession. We use this approach to identify common trajectories of neighborhood racial change among blacks, whites, Latinos, and Asians from 1970 to 2010 in the New York, Los Angeles, Chicago, and Houston metropolitan areas. We show that many nominally integrated neighborhoods have experienced gradual succession. For blacks, this succession has caused the gradual concentric diffusion of the ghetto; in contrast, Latino and Asian growth has dispersed throughout both cities and suburbs in the metropolitan areas. Durable integration has come about largely in the suburbs.

Keywords: racial segregation; racial integration; neighborhood change; New York; Los Angeles; Chicago; Houston

Citation: Bader, Michael D. M., and Siri Warkentien. 2016. "The Fragmented Evolution of Racial Integration since the Civil Rights Movement." Sociological Science 3: 135-166.

Received: February 13, 2015

Accepted: May 31, 2015

Published: March 2, 2016

Editor(s): Jesper Sørensen, Olav Sorenson

DOI: $10.15195 / \mathrm{v} 3.28$

Copyright: (C) 2016 The Author(s). This open-access article has been published under a Creative Commons Attribution License, which allows unrestricted use, distribution and reproduction, in any form, as long as the original author and source have been credited. (0)(1)
$R^{\text {ECENT studies have been relatively optimistic about the prospects of long-term }}$ racial integration in American neighborhoods. Several argue that racial residential integration is becoming much more common, and one study by Glaeser and Vigdor (2012) even goes as far as claiming the "end of segregation" (Ellen 2000; Maly 2005). ${ }^{1}$ The waning of racial segregation would be welcome news given its association with persistent racial inequality in American society (DuBois [1899]1996; Drake and Cayton [1945]1993; Massey and Denton 1993).

In the most comprehensive study of neighborhood racial change published to date, Logan and Zhang (2010) share much of this optimism. They clearly show that white flight, once the primary cause of racial segregation, has not existed in U.S. metropolitan areas since at least the 1980s. In place of white enclaves maintained by flight, they find a rapidly growing number of "global neighborhoods" in which white, black, Latino, and Asian residents are all present.

Despite the reasons for optimism, there is also cause for concern. Logan and Zhang (2010) are troubled by the growing number of single-minority segregated neighborhoods (see also Friedman 2008). Logan and Zhang (2010:1105) conclude their study by warning of a "new type of polarization...between a zone of increasing diversity and a minority zone where whites are unlikely to ever venture."

We argue that even Logan and Zhang's (2010) equivocal endorsement of racial integration is overly optimistic. We contend that previous studies underestimate 
the likelihood that integrated neighborhoods segregate over time. The reason for underestimating segregation is that existing studies cannot detect long-term, gradual racial succession. The transition models on which they rely measure only whether a group that was not previously present becomes present; or, alternatively, whether a group that was present in a neighborhood is no longer present. But measuring only the presence of racial groups means that they do not measure how the racial composition of various neighborhoods changes over time. As a result, the nominally integrated neighborhoods reported in those studies conflate sustained, durable integration and gradual racial succession.

We support our argument with evidence that we obtained using an innovative method to study neighborhood racial change. Growth mixture models use information about the initial and changing composition of racial groups to identify common trajectories of racial change. The identified trajectories were based on when and how fast the white, black, Latino, and Asian shares of the population grew or declined over time. This approach allowed us to distinguish neighborhoods that experienced long-term durable integration from those that experienced gradual racial succession. We applied this method to data measuring white, black, Latino, and Asian racial composition from 1970 to 2010 in the metropolitan neighborhoods of the four largest cities in the United States: New York, Los Angeles, Chicago, and Houston. We examined the spatial patterns of change by mapping which neighborhoods followed different racial change trajectories. These results allow us to describe the evolution of racial change in metropolitan areas since the height of the Civil Rights Movement, including the slow segregation that has occurred in and around many minority neighborhoods.

\section{Neighborhood Stability and Change after the Civil Rights Movement}

To explain why we believe a new approach to neighborhood racial change is necessary, we briefly describe types of neighborhood change that might come about in post-Civil Rights era metropolitan areas. We discuss these in three broad categories: durably segregated neighborhoods; neighborhoods experiencing racial change; and durably integrated neighborhoods. Our aim is not to be exhaustive of all possible ways that neighborhoods may change. Rather, we wish to illustrate why measuring change based on transition models might miss important aspects of more gradual racial change. Table 1 summarizes these potential trajectories.

\section{Durable Segregation}

The first set of neighborhoods are durably segregated neighborhoods that experience little racial change. A single racial group dominates the composition of the neighborhood over many decades. Durably segregated black neighborhoods fit this description (summarized in the first row of Table 1). These neighborhoods are the product of pre-Civil Rights apartheid created by housing and urban development policies (Jackson 1985; Massey and Denton 1993; Sugrue 1996). Existing research 
Table 1: Potential neighborhood racial change trajectories in post-Civil Rights America

\begin{tabular}{|c|c|c|c|}
\hline Potential Trajectory & Timing & Racial Change & Outcome \\
\hline \multicolumn{4}{|l|}{ A. Durable segregation } \\
\hline Black segregation & Ongoing & No change & Stable segregation \\
\hline White segregation & Before 1980 & No change & Stable segregation \\
\hline \multicolumn{4}{|l|}{ B. Racial change } \\
\hline White flight neighborhoods & $1970 s$ & $\begin{array}{l}\text { Black entry and rapid growth; } \\
\text { rapid White decline }\end{array}$ & Stable segregation \\
\hline Gradual Black succession & 1970s \& 1980s & $\begin{array}{l}\text { Gradual Black growth; grad- } \\
\text { ual White decline }\end{array}$ & Long-term re-segregation \\
\hline $\begin{array}{l}\text { Gradual Latino \& Asian suc- } \\
\text { cession }\end{array}$ & $\begin{array}{l}\text { Periods of im- } \\
\text { migration }\end{array}$ & $\begin{array}{l}\text { Gradual immigrant group } \\
\text { growth; gradual incumbent } \\
\text { group decline }\end{array}$ & Long-term re-segregation \\
\hline \multicolumn{4}{|l|}{ C. Durable integration } \\
\hline Quadrivial neighborhood & $1980 s$ & $\begin{array}{l}\text { Gradual growth by one group, } \\
\text { followed by second and third; } \\
\text { very slow White decline }\end{array}$ & Integration \\
\hline $\begin{array}{l}\text { Racial reversal (gentrifica- } \\
\text { tion) }\end{array}$ & $1990 \mathrm{~s}$ & $\begin{array}{l}\text { Inflections in racial change: } \\
\text { minority growth to decline \& } \\
\text { White decline to growth }\end{array}$ & $\begin{array}{l}\text { Integration; potential re- } \\
\text { segregation }\end{array}$ \\
\hline
\end{tabular}

suggests that all-black neighborhoods are likely to remain durably segregated (Friedman 2008; Logan and Zhang 2010, 2011).

All-white neighborhoods, however, have declined dramatically (summarized in the second row of Table 1). One highly publicized paper even declared allwhite neighborhoods "effectively extinct" (Glaeser and Vigdor 2012). Whites, once resistant to living among minorities, are now more tolerant to accepting them as neighbors (Krysan and Bader 2007; Farley 2011). In addition, federal policies that outlawed housing discrimination and provided opportunities for minority economic advancement have made it possible for minorities to move into previously all-white neighborhoods (Ellen 2000; Glaeser and Vigdor 2012). For these reasons, it is unlikely for all-white neighborhoods to continue to be durably segregated.

\section{Racial Change}

White flight and rapid racial succession. White flight from minorities is one of the major factors that created the pattern of racial apartheid in U.S. cities, and it is still popularly cited as a reason for continued segregation. Neighborhood transitions occurred quickly when whites, who feared or abhorred integration with minorities, left neighborhoods in large numbers (summarized in the third row of Table 1). Though white flight was common historically, Logan and Zhang (2010) found no evidence of white flight since 1980. Thus, they argue, it is unlikely to play much of a role in the maintenance of segregation. 
Gradual racial succession. Our argument rests on the idea that segregation is possible even in the absence of white flight. We contend that gradual racial succession has become the predominant form of racial segregation since Congress passed Civil Rights legislation in the 1960s. The mechanism that creates gradual racial succession, we believe, is whites' avoidance of neighborhoods with more than a few minorities. Whites' tolerance of integration that occurs when minorities move to their neighborhoods does not extend to a desire for integrated neighborhoods. Whites know less about and are resistant to considering neighborhoods with more than a token number of minorities (Krysan and Bader 2007, 2009; Lewis, Emerson, and Klineberg 2011). Therefore, a white family that leaves an integrated neighborhood is unlikely to be replaced by another white family moving into it. Even if whites do not flee at the mere presence of minorities, they might move for myriad other reasons including marriage, divorce, and job relocation. Inversely, minority families find integrated neighborhoods attractive (Charles 2000; Lewis, Emerson, and Klineberg 2011), and they are likely to fill the vacancies created by departing whites. The result is that minority families move into neighborhoods inhabited by long-term white residents aging in place. As minorities fill the vacancies left by departing whites and the whites aging in place begin to pass away, the neighborhood will experience a slow but steady march toward racial succession, a process that ethnographer Harvey Molotch (1969) called "racial change in a stable community."

Gradual succession likely emerged at different times for blacks, Latinos, and Asians. Institutional housing discrimination that occurred before the Fair Housing Act prevented blacks from searching outside of ghettos, and led to pent-up housing demand (Sugrue 1996). Black families fleeing the crowded ghetto neighborhoods would likely have searched in nearby neighborhoods; they would be more familiar with nearby neighborhoods, be closer to friends and family members, and be less racially isolated (Krysan and Farley 2002; Krysan and Bader 2009). This leads us to suspect that gradual black succession started in the 1970s near traditional black enclaves (summarized in the fourth row of Table 1).

Latino and Asian gradual succession has likely depended on patterns of immigration to metropolitan areas (summarized in the fifth row of Table 1). Migrants have typically relied on social networks to find housing and thus looked in traditional enclaves where friends or family already lived (Massey and Espinosa 1997; Palloni et al. 2001). These social networks would have led the immigrant group to increase quickly and the existing group-usually but not necessarily whites-to decline (Denton and Massey 1991; Clark 1993; Iceland 2004). Unless whites fled the neighborhood, housing vacancies would have been limited for the incoming immigrants, and this would have forced them to seek housing in neighborhoods close to but outside the traditional enclave. The spill-over of excess housing demand would have caused neighborhoods near enclaves to become vulnerable to racial succession (Denton and Massey 1991; Crowder, Hall, and Tolnay 2011). Therefore, both existing enclaves and neighborhoods adjacent to them would be at risk of gradual succession when the metropolitan area experienced high levels of immigration by a group. 


\section{Durable Integration}

Neighborhoods could also experience what we call durable integration, based on two criteria. First, the neighborhood should comprise multiple racial groups. This criterion also requires that none of those groups should drastically outnumber other groups, at least relative to the overall metropolitan population. Second, the pace of racial change should indicate that those multiple groups should remain present over several decades. Durable integration occurs, therefore, when multiple groups share a neighborhood and the pace at which any racial group grows (or declines) in the neighborhood is not substantially faster than the pace of metropolitan growth (or decline) of the same group.

Quadrivial neighborhoods. The ideal type of integration occurs when neighborhoods become a microcosm of the metropolitan population. We call neighborhoods where whites, blacks, Latinos, and Asians coexist for several decades "quadrivial neighborhoods," derived from the Latin meaning "four paths coming to an intersection" (summarized in the penultimate row of Table 1). Logan and Zhang (2010) have called similar neighborhoods "global neighborhoods," which they defined as neighborhoods shared among the four racial groups in roughly proportionate numbers to their metropolitan populations. In their analysis, Logan and Zhang (2010) draw a comparison between global neighborhoods and Sassen's (1991) idea of "global cities" based on the immigration patterns and international diversity reflected in the neighborhoods. We prefer to use the term "quadrivial" because we focus exclusively on racial composition and not the national origin of residents, as "global" neighborhoods implies. Both Latino and Asian growth occurs both through immigration and births, so much so that the Latino population now grows more from births than from immigration (Stepler and Brown 2015).

Prior research on neighborhoods with all four groups present suggests that they are durably integrated (i.e., they have multiple racial groups present for multiple decades) (Logan and Zhang 2010). But these analyses only tell us whether multiple groups are present in the neighborhood; they do not tell us how the composition among those groups present might have changed. We cannot tell whether the composition among groups remained stable or whether the share of one group was growing rapidly at the expense of another. In addition, existing theory does not provide insight into where this trajectory would come about, and there has been no ecological analysis of neighborhoods following this trajectory to date (Logan and Zhang 2010).

Racial reversal due to gentrification. The historical path of segregation has led researchers to focus primarily on integration occurring because minorities move to white neighborhoods. Integration can also be created by whites moving to minority neighborhoods. This type of racial change is most often associated with the gentrification of urban neighborhoods, and evidence suggests that a growing percentage of whites accompanies economic gentrification in neighborhoods (Wyly and Hammel 1999). The typical understanding of the gentrification process posits that the percentage of whites declines in a neighborhood before gentrification. The start of gentrification brings about the reversal of this trend so that the percentage of whites 
increases while minority growth slows and then declines (summarized in the final row of Table 1). It is possible for gentrification to end with complete re-segregation by whites, in which case the change would register in transition models. But in cases where minorities remain present in the neighborhood, transition models will miss the inflection of white decline into growth and minority growth into decline. As a result, transition models could underestimate the number of neighborhoods undergoing this trajectory of racial change.

\section{Gradual Succession or Durable Integration? The Fragmentation of "Integrated" Neighborhoods}

The prospect of racial integration in the twenty-first century depends on whether currently "integrated" neighborhoods are undergoing gradual racial succession or experiencing durable racial integration. If a substantial number of nominally integrated neighborhoods are experiencing gradual racial succession, then the rise of the "new polarization" (Logan and Zhang 2010) is far more troubling than if most neighborhoods remain durably integrated. But distinguishing between neighborhoods undergoing gradual succession or durable integration becomes difficult if one does not know how quickly the composition of racial groups is changing.

This problem is unique to the post-Civil Rights Movement era. Before the Civil Rights Movement, there was little racial change in neighborhoods. When change did occur, it occurred quickly as a result of white flight (Taeuber and Taeuber 1965). Transition models could capture these rapid changes quite well. But Civil Rights legislation and changing racial attitudes increased the possibility that neighborhoods considered to be "integrated neighborhoods" underwent different trajectories of racial change. The fragmentation into multiple trajectories affects how we assess progress toward racial residential integration. Assessing only the presence of groups does not capture the different trajectories of long-term change in racial composition that are now likely to exist. To correct this problem, we should study whether particular groups are growing disproportionately fast relative to other groups also present in the neighborhood.

\section{Methods and Data}

To distinguish between gradual racial succession and durable integration, we used growth mixture models to identify common trajectories based on the timing and pace of neighborhood racial change. Growth mixture models can accommodate multiple outcomes and identify trajectories based on the simultaneous changes of multiple racial groups. This is an improvement over previous research that only examined growth rates of a single race relative to all other racial groups (Denton and Massey 1991; Ellen 2000).

This method also improves on transition matrices, which have been the dominant method of studying neighborhood racial change for half a century. Transition matrices identify the probability of transitioning between states at two different 


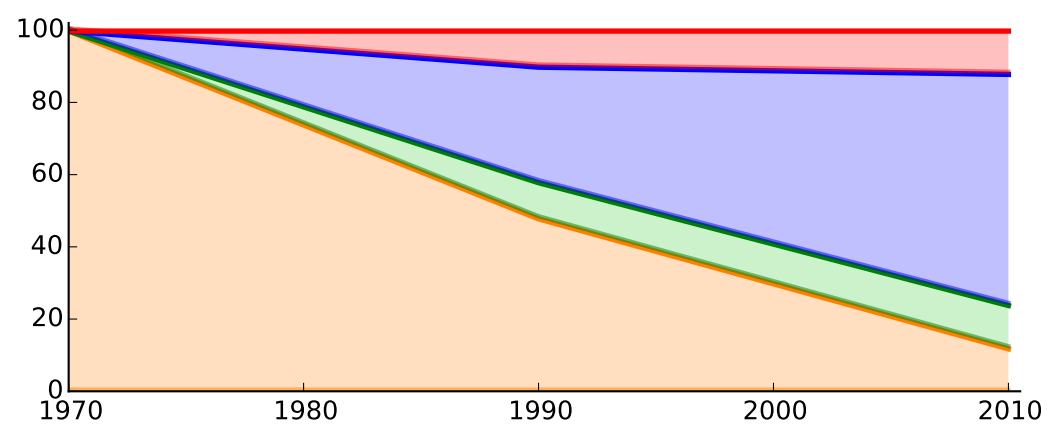

(a) Neighborhood A. Gradual racial succession

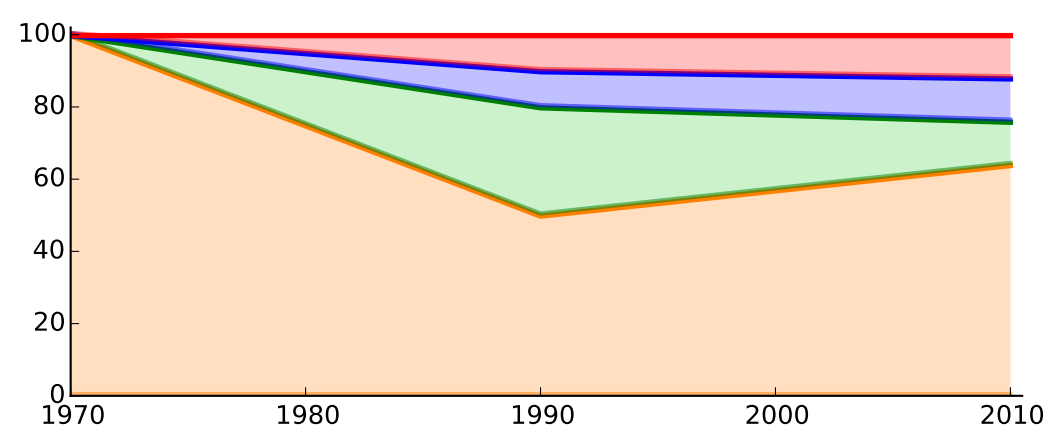

(b) Neighborhood B. Gentrification

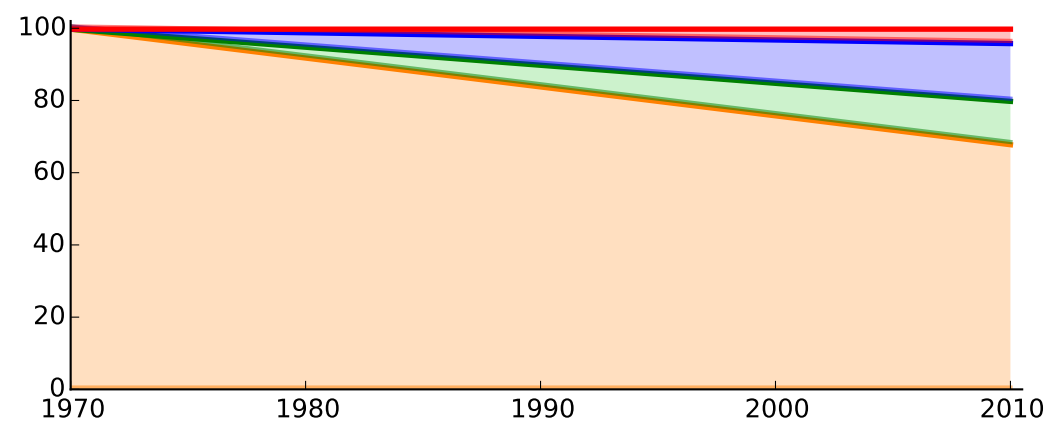

(c) Neighborhood C. Durable integration

\section{Legend}

Non-Latino white

Non-Latino black

Latino

Asian

Figure 1: Hypothetical neighborhood racial change trajectories in post-Civil Rights Movement United States 
points in time. The states are defined by the presence of different racial groups based on thresholds arbitrarily set by the analysts. The biggest problem with transition matrices is that they only provide a coarse measure of racial change: either a group gains enough people to be marked as present or loses enough that it is considered absent. Substantial racial changes that do not cause a group to cross the threshold are not registered. Recent studies pieced together transitions from consecutive decades to examine long-term racial change (Friedman 2008; Logan and Zhang 2010), but the method cannot identify gradual racial change.

To demonstrate the problem we plot the racial change for three hypothetical neighborhoods in Figure 1, all of which start as all-white in 1970. Neighborhood A experienced gradual succession. After 1970 it experienced 16 percent Latino growth per decade. The percentage of Blacks and Asians both grew at five percent per decade in the 1970s and 1980s and one percent per decade in the 1990s and 2000s. By 2010, Latinos made up 64 percent of the neighborhood and each of the other groups made up 12 percent.

Neighborhood B gentrified. From 1970 to 1990, the percentage of blacks increased to 30 percent while Latinos and Asians both increased to 10 percent of the population (meaning whites made up half of the population). From 1990 to 2010, the percentage of whites increased by seven percent per decade, blacks decreased by nine percent per decade, and Latinos and Asians both increased by one percent per decade. The result in 2010 is a neighborhood that is 64 percent white, with blacks, Latinos, and Asians each making up 12 percent of the neighborhood.

Neighborhood C was a durably integrated quadrivial neighborhood. After 1970 it experienced four percent growth of Latinos, three percent growth of blacks, and one percent growth of Asians per decade. The result in 2010 is a neighborhood that resembles the composition of the United States: 68 percent white, 16 percent Latino, 12 percent black, and four percent Asian.

Despite the substantial differences in these three neighborhoods, transition matrices measuring change from 1980 to 2010 would classify all three neighborhoods as stable quadrivial neighborhoods. They would all likely transition into different categories by 2020, but for analysts to capture the entirety of the change from 1980 to 2020 would require that they construct a transition matrix with 759,375 cells! Growth mixture models offer a compelling alternative because they classify neighborhoods based on similarity in the actual composition of the neighborhood. It would classify these three neighborhoods into different trajectories based on the differences in the slope and inflections in the racial group change.

\section{Formal Model of Racial Change Trajectories}

To distinguish racial change trajectories using a growth mixture model, we model the percentage of each racial group in a neighborhood as a function of the initial proportion of residents in the racial group in 1970 (the first population census after Civil Rights legislation passed) and the change in the proportion of residents of each group in the subsequent four decades. Our model, shown in Equation (1), predicts the composition of racial group $r$ in neighborhood $j$ at time $t, p_{t j}^{r}$. Because 
the outcome is a series of proportions, values of the outcome $p_{t j}^{r}$ were transformed using the function $\eta_{r}=\arcsin \left(p_{t j}^{r \frac{1}{2}}\right)$.

$$
\begin{aligned}
\eta_{t j \mid c=k}^{r} & =\beta_{0 k j}^{r}+\beta_{1 k j}^{r} t+\beta_{2 k j}^{r} t^{2} \beta_{3 k j}^{r} t^{3}+e_{t j}^{r} \\
\beta_{0 k j}^{r} & =\gamma_{k 0}^{r}+u_{0 j}^{r} \\
\beta_{1 k j}^{r} & =\gamma_{k 1}^{r} \\
\beta_{2 k j}^{r} & =\gamma_{k 2}^{r} \\
\beta_{3 k j}^{r} & =\gamma_{k 3}^{r}
\end{aligned}
$$

We measured the pace of racial change by the (transformed) percentage point change per decade, meaning that we indexed time such that $t=0$ in $1970, t=1$ in 1980 , and $t=4$ in 2010. We estimated four parameters for each racial group in the model. The intercept parameter, $\beta_{0 j}^{r}$, was the proportion of residents in racial group $r$ in 1970. The second line of Equation (1) shows that we modeled the intercept using a fixed coefficient, $\gamma_{0}^{r}$, and a component that measured the unique deviation of each neighborhood from the initial (transformed) proportion of racial group $r$, $u_{0 j}^{r}$. We assumed that these unique deviations from the intercept were normally distributed around a mean of zero with variance $\tau_{0}^{r 2}$.

The remaining parameters reflected change components: $\beta_{1 j}^{r}$ modeled the linear pace of change per decade, $\beta_{2 j}^{r}$ the quadratic change in pace, and $\beta_{3 j}^{r}$ the cubic inflection in the changing pace. We estimated each of these coefficients by a corresponding fixed coefficient, $\gamma^{r}$. In theory, it would have been desirable to estimate the variance for the slope, quadratic, and cubic terms; however, the limitations of our empirical data given the complexity of the model made it impossible to freely estimate these variances and achieve model convergence. We assumed a normally distributed unique component of change in the proportion of residents in group $r$ at time $t$ within neighborhood $j, e_{t j}^{r}$ with a mean of zero and variance of $\sigma_{t j}^{r 2}$.

The model classifies the distribution of racial group proportions within neighborhoods over time as a mixture of $K$ distinct distributions (latent classes). These $K$ distinct distributions reflect the distinct trajectories of racial change in the postCivil Rights Movement era. The model identified neighborhood $j$ as belonging to trajectory $k$, and the estimation of the (transformed) proportion of racial group $r$ was conditioned on class membership (i.e., $\eta_{t j \mid c=k}^{r}$ ). Each fixed component of the equation includes the subscript $k$ which demonstrates that the fixed parameter estimates differed across each of $K$ trajectories. This allowed different intercept $\left(\gamma_{k 0}^{r}\right)$, linear $\left(\gamma_{k 01}^{r}\right)$, quadratic $\left(\gamma_{k 2}^{r}\right)$, and cubic $\left(\gamma_{k 3}^{r}\right)$ coefficients to be predicted for each trajectory model. All parameters in Equation (1) were estimated using maximum likelihood in the EM algorithm (Muthén and Shedden 1999) using Mplus 7.1.

We use the arcsine square-root transformation (i.e., $\arcsin \left(p_{t j}^{r^{\frac{1}{2}}}\right)$ ) to stabilize the variance of the proportions in our model. From our description above, one will note that our model includes parameters for the variance of time-specific racial changes and neighborhood-specific differences in the intercept $\left(\sigma_{t j}^{r 2}\right.$ and $\tau_{0}^{r 2}$, respectively). Using the arcsine square-root transformation prevents collinearity between the 
variance estimates and the group proportions, which can create estimation and convergence problems for the model. The advantage that we gain by eliminating this collinearity comes with two costs. First, we lose the linear accounting relationship across proportions that, together, sum to one. Losing the linear accounting relationship could introduce errors by allowing proportions to sum to a value other than one. The loss of the accounting relationship also reduces the interpretability of the models. To make the estimates more interpretable we re-transformed our results back to represent proportions. ${ }^{2}$ Second, we risk underestimating changes where proportions are close to zero or one (Jaeger 2008). Since values close to either zero or one reflect segregated neighborhoods, the bias introduced by the transformation could underestimate the true level of segregation. Our hypothesis contends that current studies already underestimate segregation; therefore, using the arcsine square-root transformation in our analysis will bias our findings against our hypothesis.

\section{Decision Criteria}

Growth mixture models are a relatively new type of statistical model. Distinguishing the appropriate number of classes (trajectories in our case) is a topic of ongoing debate about these models. The goal in all cases is to identify the smallest number of necessary classes that sufficiently describe the heterogeneity in the population (Petras and Masyn 2010).

We ran a series of models that sequentially increased the number of trajectories estimated. We started with nine trajectories based on Bader (2009), who found nine trajectories of racial change in Chicago from 1970 to 2000. We used a combination of three measures to decide on the appropriate number of trajectories. First, we used the Bayesian information criterion (BIC), which measures increases to model information relative to the number of parameters added to the model. Second, we used the Lo-Mendel-Rubin likelihood ratio test (LMR-LRT), which indicates how well a model with one more class fits the data compared to the model with one less class. Third, we used an entropy measure that assesses the probability that neighborhoods are classified into their most-likely latent class with high probability. We looked across models with successive numbers of trajectories, $k$, to identify the model with a combination of lowest BIC value, a significant LMR-LRT value $(p<0.05)$, and high entropy. Since decision criteria are not well established, we also examined the correspondence between models with one more trajectory and one fewer in order to confirm the robustness of our trajectory identification.

\section{Data Sources}

We used the Longitudinal Tract Database (LTDB) to measure the proportion of each racial group in metropolitan neighborhoods from 1970 to 2010. The LTDB compiled racial data from the tabulated reports of the United States Census from five censuses (1970-2010) and normalized the data to 2010 Census boundaries (Logan, Xu, and Stults 2014). We measured racial composition as the proportion of residents who identified as non-Latino white, non-Latino black, Asian, or Latino of any race. The dependent variables were the number identifying as each race divided by the sum 
of whites, blacks, Asians, and Latinos multiplied by 100. As a result, all percentages summed to 100 .

Census changes to race and ethnicity measures presented challenges. The Census options regarding Asian race changed several times from 1970 to 2010. We recoded the data from each Census to represent the category "Asians or Pacific Islanders," since this was the most inclusive definition used during the period. In addition, the Census Bureau started tabulating Latinos by race in 1980. Therefore, Latinos were included in the 1970 counts of whites and blacks. We employed the strategy Timberlake and Iceland (2007) used to allocate Latinos to racial categories in 1970 based on the proportion of Latinos identifying as white or black in the same tract in 1980. This decision means that we might have underestimated the level of change in the Latino population from 1970 to 1980.

The LTDB, however, does not include data to calculate the non-Latino white and black population in 1970. For the calculation we used the Neighborhood Change Database (NCDB), which included variables from 1970-2000 normalized to 2000 Census boundaries (Tatian 2003). Following the recommendation of Logan and colleagues (2014), we calculated values for variables that only existed in the NCDB by taking the value of the variable normed to the 2000 Census tract geography. We then used the crosswalk provided by the LTDB to calculate the value of the variable in 2010 tract geography.

\section{Study Regions}

We studied the metropolitan areas surrounding the four most populous cities in 2010: New York, Los Angeles, Chicago, and Houston. These four metropolitan areas comprised 15 percent of the 2010 U.S. population. Although this was a small sample, the sample provided variation on significant attributes. Each of the cities is in a different Census region (Northeast, West, Midwest, and South). They are a mix of very old and very young cities. And, most importantly, they each had unique histories of racial segregation, racial tension, and racial change.

Focusing on a small number of metropolitan areas allowed us to focus on the specific geography of racial change in each metropolitan area. After estimating our models, we assigned each neighborhood to the trajectory the model estimation indicated it most likely followed. We then mapped the trajectories for each of the four metropolitan areas. These maps summarized the spatial and temporal features of neighborhood racial change, which would have been impractical to do with a larger sample.

\section{The Timing and Pace of Neighborhood Racial Change after the Civil Rights Movement}

We found that neighborhoods have followed 11 racial change trajectories since the height of the Civil Rights Movement. We plotted these 11 unique racial change trajectories in Figure $2{ }^{3}$ We assigned each trajectory a name based on the predicted racial change trajectory and grouped them into zones of segregation (black, Latino, and Asian) or integration, each of which we describe below. 

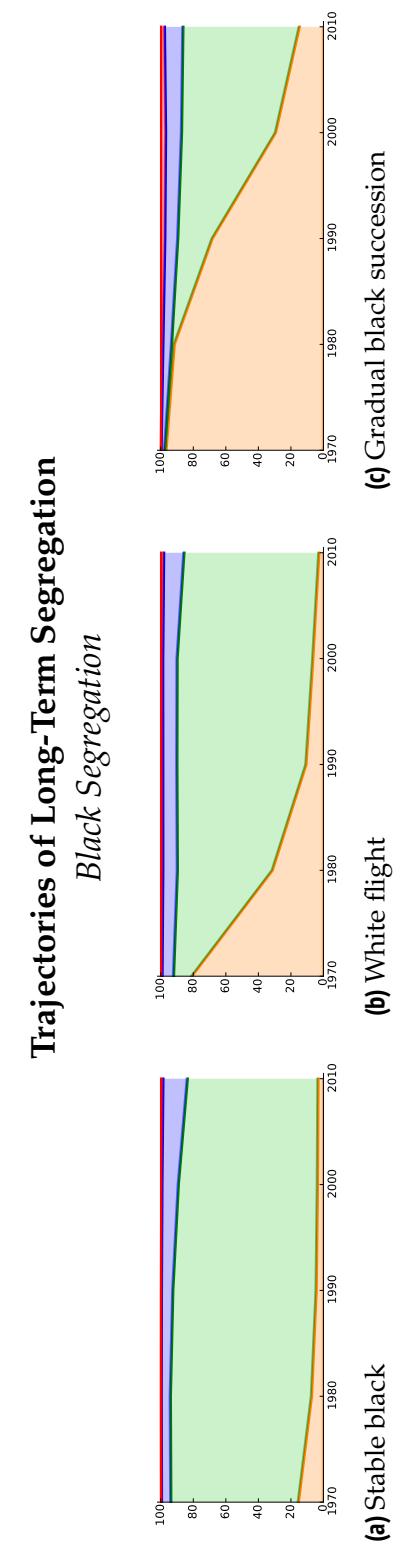

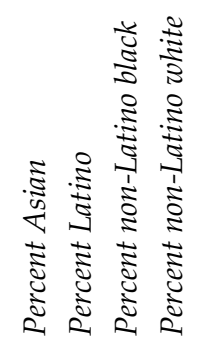

鳏
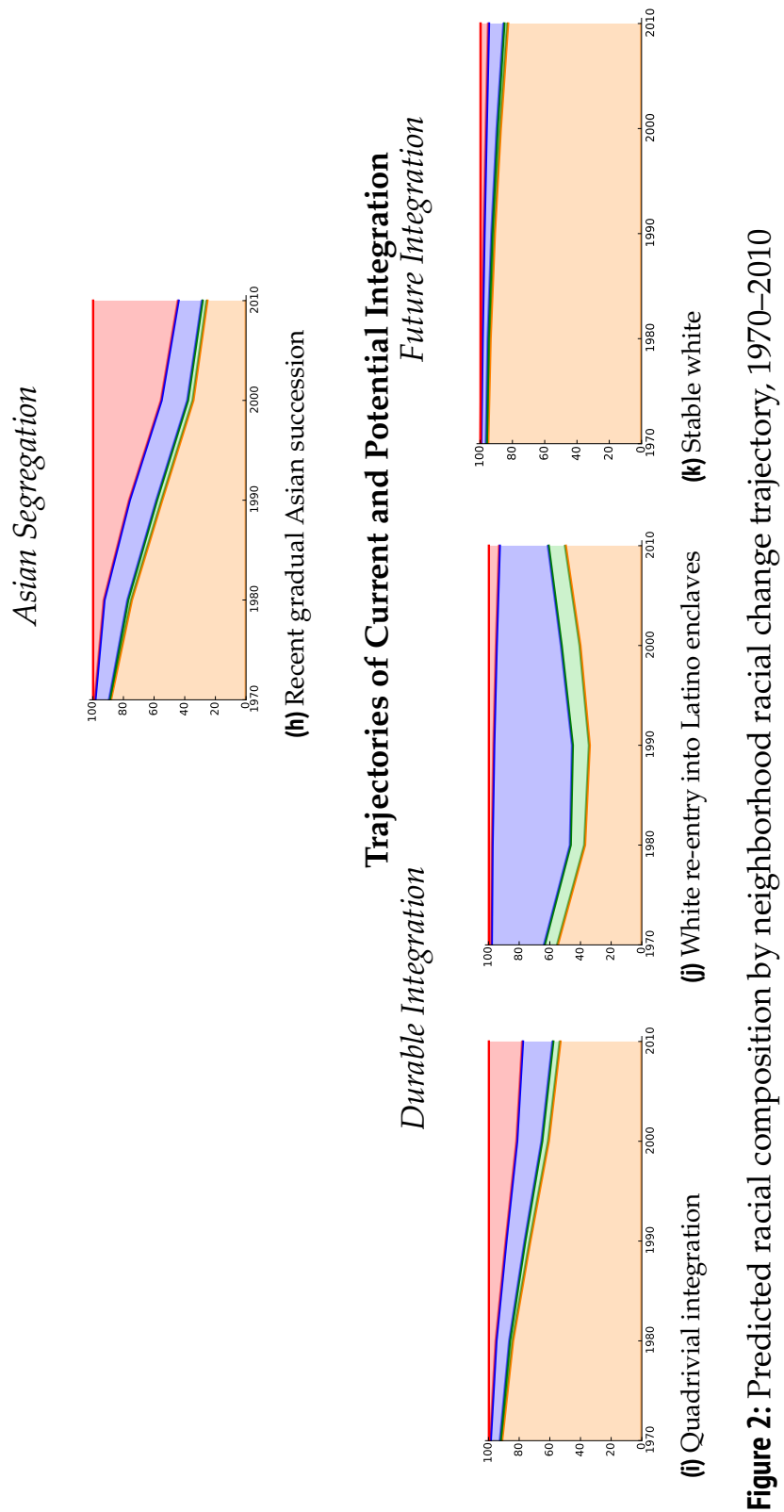

March 2016 | Volume 3 


\section{Zone of Black Segregation}

Stable black. Neighborhoods that followed the stable black trajectory (plotted in Figure 2a) remained durably segregated during the four decades after passage of the Fair Housing Act. The share of blacks hovered around 85 percent for most of this time. As the share of Blacks remained stable, the racial identity of blacks' neighbors changed from predominantly white in 1970 to predominantly Latino by 2010. These neighborhoods made up eight percent of the metropolitan neighborhoods.

White flight neighborhoods. Two trajectories of black growth came about in neighborhoods that had predominantly white populations in 1970. The first follows the white flight pattern of racial succession described by Duncan and Duncan (1957, plotted in Figure 2b). The white share of residents dropped 50 percentage points from 1970 to 1980 alone. The rapid decline continued after 1980, and by 2010 whites made up only three percent of the population in these neighborhoods. The increasing share of blacks mirrored the decreasing share of whites during this period. The Latino population also grew, making up 12 percent of residents in 2010. Four percent of neighborhoods followed this trajectory.

Gradual black succession. Black growth happened much more gradually in the second black growth trajectory, about 18 percentage points per decade (plotted in Figure 2c). The percentage of whites declined by about 20 percentage points per decade during the whole period. This was much slower than the 50 percent decline that occurred in white flight neighborhoods during the 1970s. Latino growth made up the remaining two percent difference. This trajectory reflects what we would expect from the passive avoidance of integrated neighborhoods by whites. Whites did not flee, but they became an increasingly smaller proportion of the population. Although whites were still present in sufficient numbers in 2010 to be considered present-and thus they would have appeared integrated based on transition models- these neighborhoods are segregating (and some have segregated). Two percent of neighborhoods followed this trajectory.

\section{Zone of Latino Segregation}

Latino enclaves. Latino segregation came about through several trajectories. The first, which represented about eight percent of metropolitan neighborhoods, was the increasing Latino concentration in traditional Latino enclaves (Figure 2d). Latinos made up 41 percent of the population in 1970, after which the Latino share of the population grew rapidly: Latinos were 74 percent of the population in 1990 before growth slowed during the 1990s and 2000s. By 2000, Latinos made up 82 percent of residents. During this period, the white share of the population declined from 50 percent of the neighborhood in 2010 to eight percent in 2010.

Post-immigration reform gradual Latino succession. Two trajectories of Latino growth started in the decade after immigration reform was signed into law. In both trajectories, Latinos made up a modest eight percent of residents in 1970 before growing by 10 percent during the 1970s and by 20 percent in the 1980s. The 
trajectories differed because that growth occurred in white neighborhoods in one trajectory (plotted in Figure 2e) and in black neighborhoods in the other trajectory (plotted in Figure 2f). The Latino share of the population grew by 30 percentage points in the formerly white neighborhoods during the 1990s before slowing to 15 percent during the 2000s. Latino growth in formerly black neighborhoods remained steady during the 1990s, growing by another 20 percent, and slowed to just seven percent during the 2000s. Both neighborhoods end up as unmistakably Latino but both would be considered integrated based on the presence of other racial groups. Eight percent of metropolitan neighborhoods followed post-reform Latino growth trajectories: five percent in formerly white neighborhoods and three percent in formerly black neighborhoods.

Recent gradual Latino succession. The final trajectory of Latino growth occurred in 13 percent of the metropolitan neighborhoods. These are neighborhoods that experienced Latino growth that started during in the 1980s (Figure 2g). Latinos made made up only 10 percent of the population in these neighborhoods as late as 1980. By 1990, the Latino population had doubled to 20 percent, and it rose to 35 percent in 2000. By 2010, almost half of residents in these neighborhoods were Latino. As the share of Latinos grew, the share of whites declined. The Asian population grew by about two percentage points per decade. While these neighborhoods appeared to follow the "incremental addition" of racial groups that Logan and Zhang (2010) describe, these neighborhoods also appear likely to become overwhelmingly Latino. This trajectory mimics that of post-reform gradual Latino succession in white neighborhoods lagged by a decade.

\section{Zone of Asian Segregation}

Neighborhoods experiencing recent Asian growth made up four percent of metropolitan neighborhoods. This trajectory (plotted in Figure $2 \mathrm{~h}$ ) looked very similar to the recent Latino growth trajectory through the 1970s and 1980s. In the 1990s, however, the Latino share of residents leveled off while the Asian share of the population increased substantially. From 1980 to 1990 Asians jumped from making up seven percent to making up 25 percent of neighborhood residents. During the 1990s, the percentage of Asians increased to 50 percent of residents. Asian growth slowed during the 2000s so that they made up 56 percent of residents in 2010. From 1970 to 2010, the percentage of whites plummeted from 90 percent to 25 percent of the population. Again, transition models would consider these neighborhoods integrated among at least whites, Latinos, and Asians, but the trajectory of change shows that the pace of Asian growth in these neighborhoods outstripped the pace of Asian growth in all four metropolitan areas over these four decades.

\section{Zone of Durable Integration}

Quadrivial integration. We identifed two trajectories that reflect patterns of durable integration. The first reflects the ideal type of quadrivial integration (plotted in Figure 2i). These neighborhoods had minimal integration in 1970: they were 91 percent white, six percent Latino, and one percent each Black and Asian. Over the 
next four decades each minority group grew at a modest but steady rate: Latinos by a little more than three percent per decade, blacks by about one percent, and Asians by about five percent. The white decline of almost 40 percent in 40 years mirrors the declining share of whites in these four metropolitan areas (and the nation) during the period. Quadrivial neighborhoods made up 15 percent of neighborhoods.

White re-entry. The second trajectory in the zone of durable integration included neighborhoods where whites returned to Latino enclaves (plotted in Figure 2j). Latinos made up 35 percent of these neighborhoods in 1970 and 51 percent in 1980. This is the same rate of growth that occurred in Latino enclaves that we described above. In the 1980s, however, Latino growth reached a plateau and then declined by ten percent per decade during the 1990s and 2000s. The share of white residents declined by 18 percentage points during the 1970s before reversing and growing during the 1990s and 2000s. The result is that whites made up almost the same percentage of the population in 2010 as they did in 1970. Despite an increasing share of whites, these neighborhoods did not appear at risk of becoming all-white and were therefore not at risk of transitioning from integrated to segregated in transition models. The return of whites to Latino enclaves occurred in four percent of neighborhoods. Together with quadrivial neighborhoods, we estimate that 19 percent of neighborhoods make up the "zone of durable integration" in these four metropolitan areas.

\section{Zone of Future Integration: Minority Footholds in Stable White Neigh- borhoods}

The most common trajectory was that in which the share of minority groups grew at a glacial pace, so that even in 2010 these neigborhoods remained overwhelmingly white. Thirty-five percent of neighborhoods followed this trajectory. In 1970, these neighborhoods were 95 percent white; in 2010, they were 83 percent white (plotted in Figure 2k). During that time, Latinos grew to ten percent of the population, Asians to five percent, and Blacks to two percent. While still overwhelmingly white, these neighborhoods would not be considered "all-white" based exclusively on measuring group presence, since minorities were one of every five residents. These neighborhoods also follow the path of increasing diversity that Logan and Zhang (2010) describe. At the pace these neighborhoods are changing, it would take blacks another two decades, Latinos four decades, and Asians six decades to match their shares in the 2010 composition of quadrivial neighborhoods.

\section{Geography of Racial Change}

The previous section shows that the timing and pace of racial change has clearly varied among neighborhoods since the Civil Rights Movement. Many nominally integrated neighborhoods were experiencing gradual succession that led to or will lead to racially segregated neighborhoods. In this section we examine the spatial distribution of neighborhoods that followed different racial change trajectories, which we found varied at two spatial scales. 


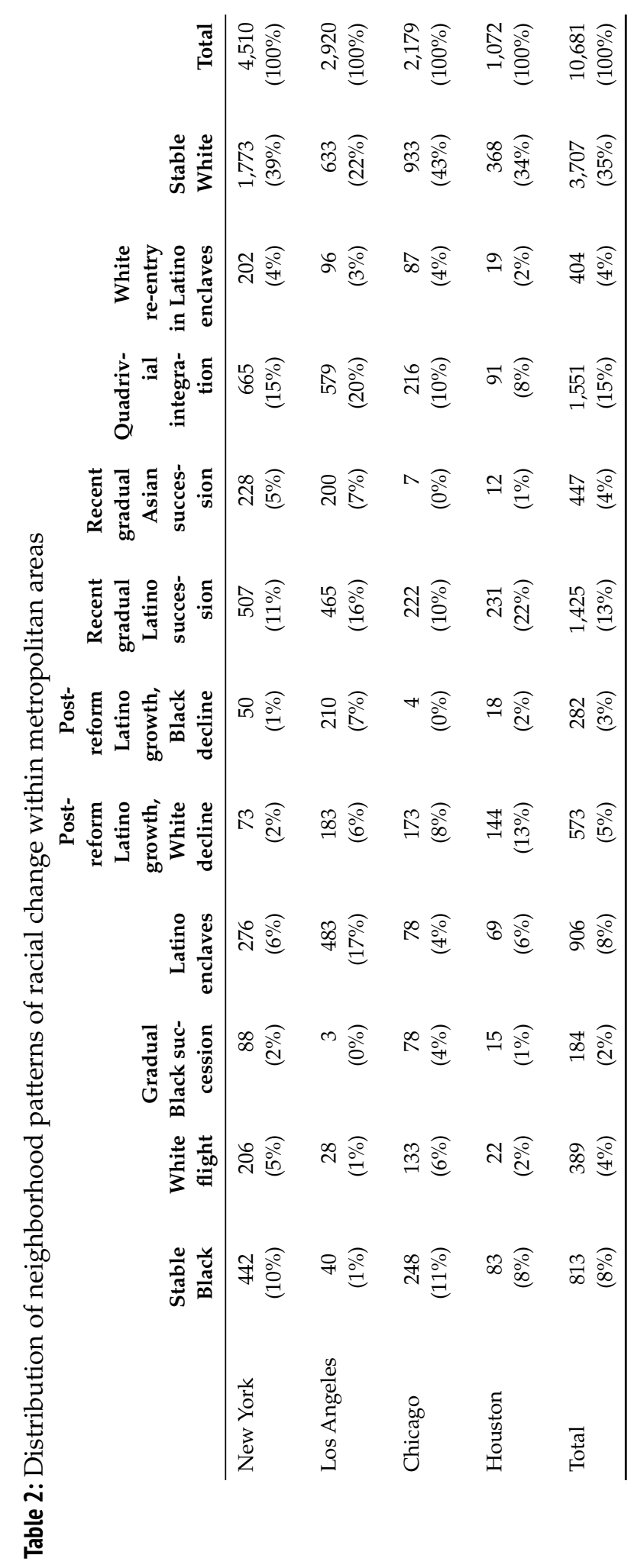




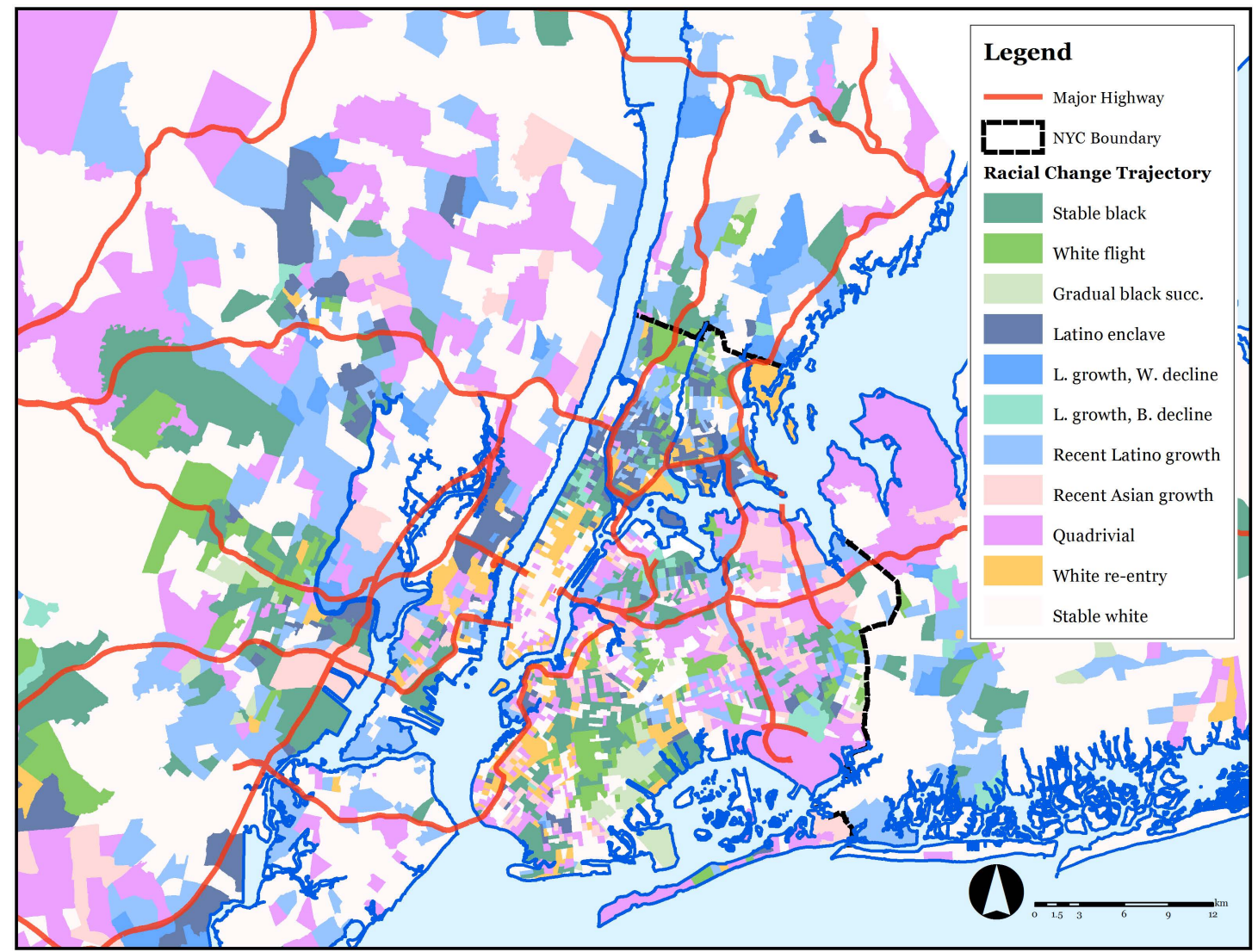

Figure 3: Map of neighborhood racial change trajectories from 1970-2010 in the New York metropolitan area (map shows a detail of neighborhoods in and near New York City; a map of the complete CMSA is available upon request)

First, the distribution of trajectories varied across metropolitan areas. Table 2 reports the percentage of neighborhoods in each metropolitan area that followed each trajectory. This variation across metropolitan areas was statistically significant $\left(\chi^{2}=1949 ;\right.$ d.f. $\left.=30 ; p<0.001\right)$. Second, neighborhoods followed trajectories based on spatial patterns within metropolitan areas. To show these patterns, we present maps of select areas near each central city in Figures 3 through 6. Interactive maps of the entire metropolitan area are available at http://mikebader . net/media/neighborhoodtrajectories/. We use Table 2 to discuss metropolitan differences in the distribution of racial trajectories and the maps to discuss variation within metropolitan locations.

\section{Zone of Black Segregation: Concentric Diffusion from Ghettos}

White flight (mapped in a mid-tone green) occurred in the neighborhoods surrounding stable black ghettos (mapped in dark green) that were created by pre-Civil Rights Movement apartheid policies. Gradual succession (mapped in light green) 


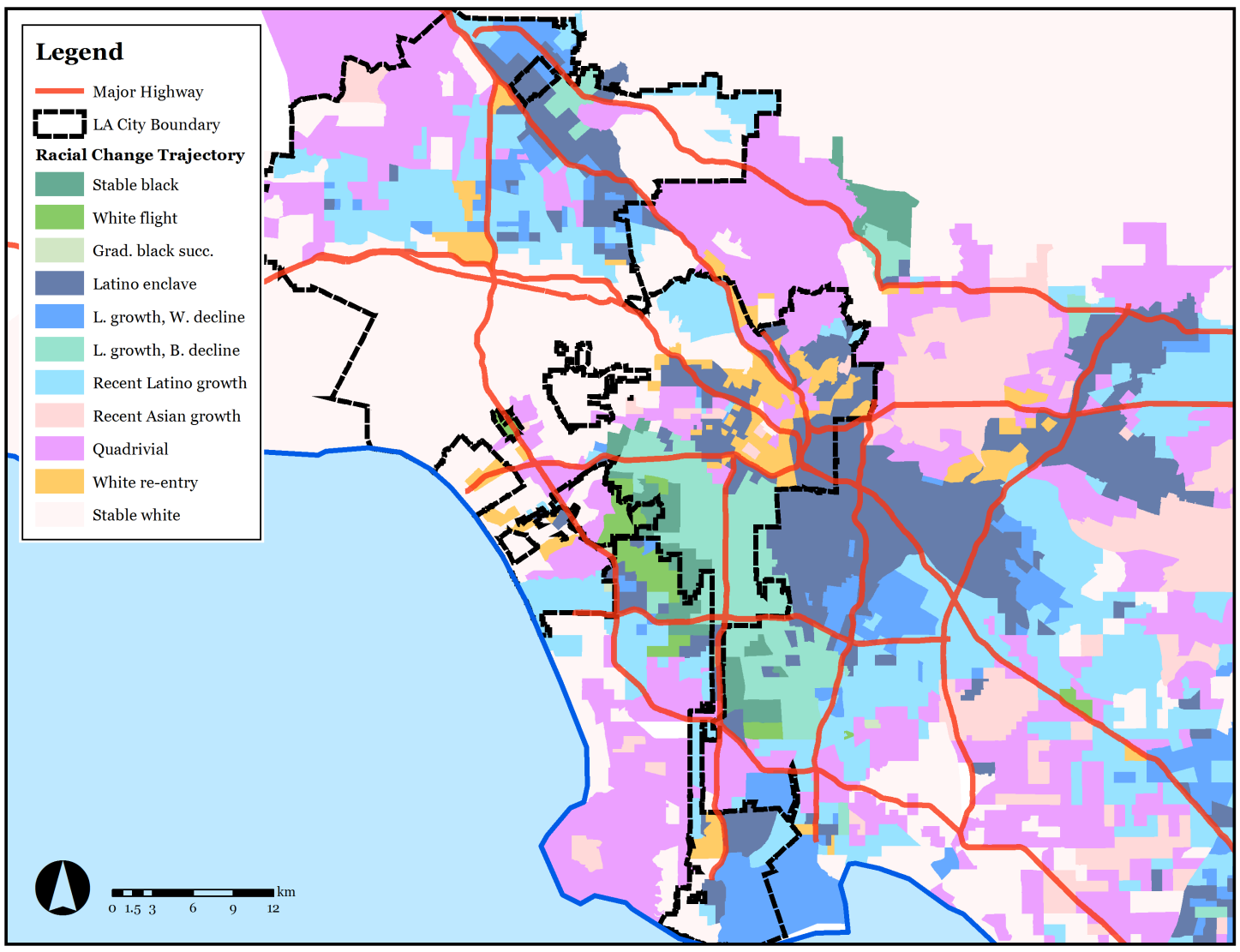

Figure 4: Map of neighborhood racial change trajectories from 1970-2010 in the Los Angeles metropolitan area (map shows a detail of neighborhoods in and near the city of Los Angeles; a map of the complete CMSA is available upon request)

then occurred in the neighborhoods surrounding the white flight neighborhoods. This concentric diffusion is the primary geographic process through which black segregation has persisted in the post-Civil Rights Movement era. Concentric diffusion was especially pronounced in neighborhoods in North Brooklyn, South-Central Los Angeles, and the South and West Sides of Chicago, all of which experienced riots during the unrest of the 1960s. ${ }^{4}$

Table 2 shows that black segregation occurred in more New York and Chicago neighborhoods than Los Angeles and Houston neighborhoods. The geographic expansion of the ghetto was also larger in New York and Chicago than in the other two metropolitan areas. Black ghettos in the smaller cities of Newark, New Jersey (which also suffered from riots in 1967) and Gary, Indiana also expanded and were subsumed into the expanding New York and Chicago metropolitan areas. In both New York and Chicago, the ghetto expanded into inner-ring suburbs, primarily as the result of gradual succession. Houston had a sizable number of stable black neighborhoods but few in which the black population grew in the post-Civil Rights era. 


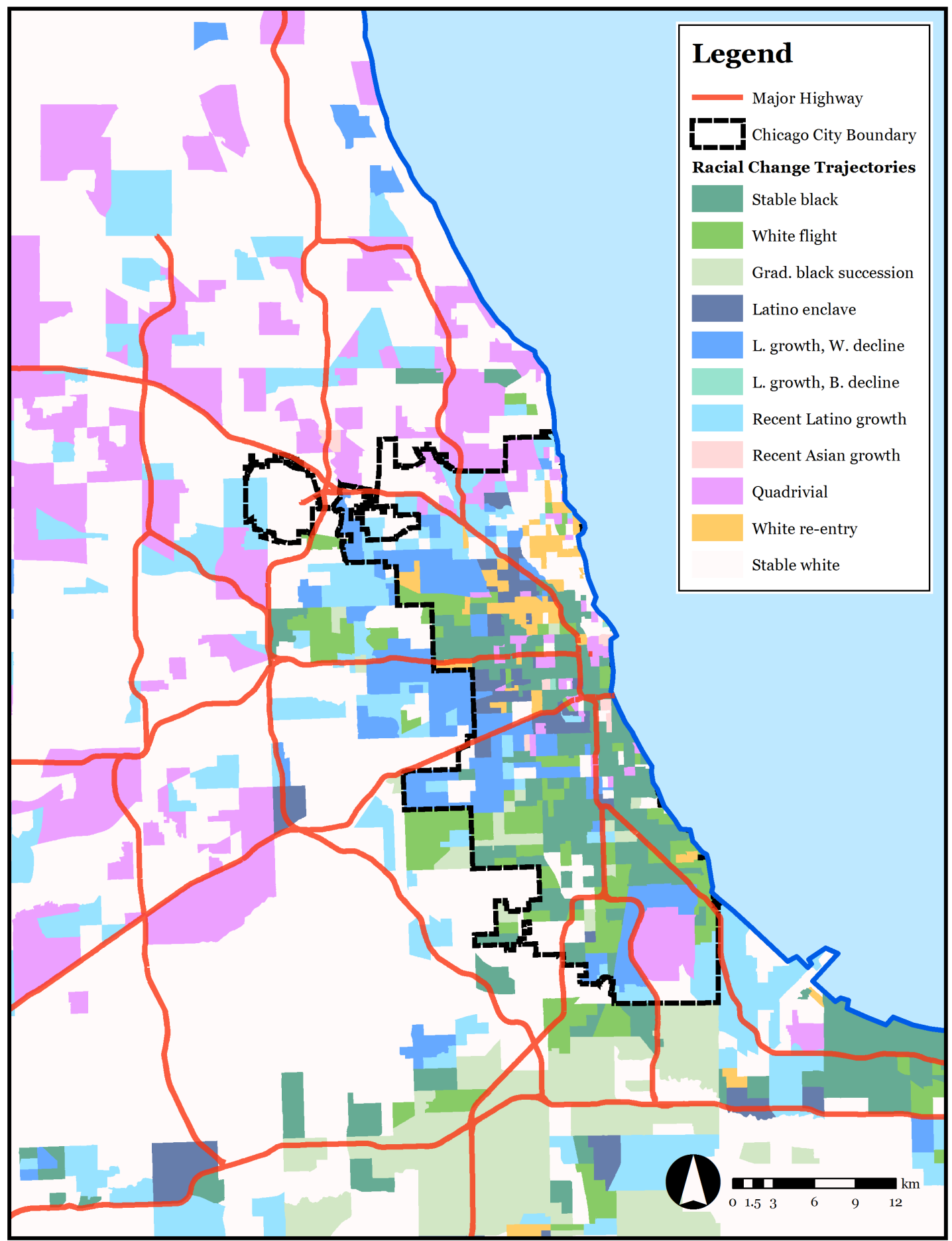

Figure 5: Map of neighborhood racial change trajectories from 1970-2010 in the Chicago metropolitan area (map shows a detail of neighborhoods in and near Chicago; a map of the complete CMSA is available upon request) 


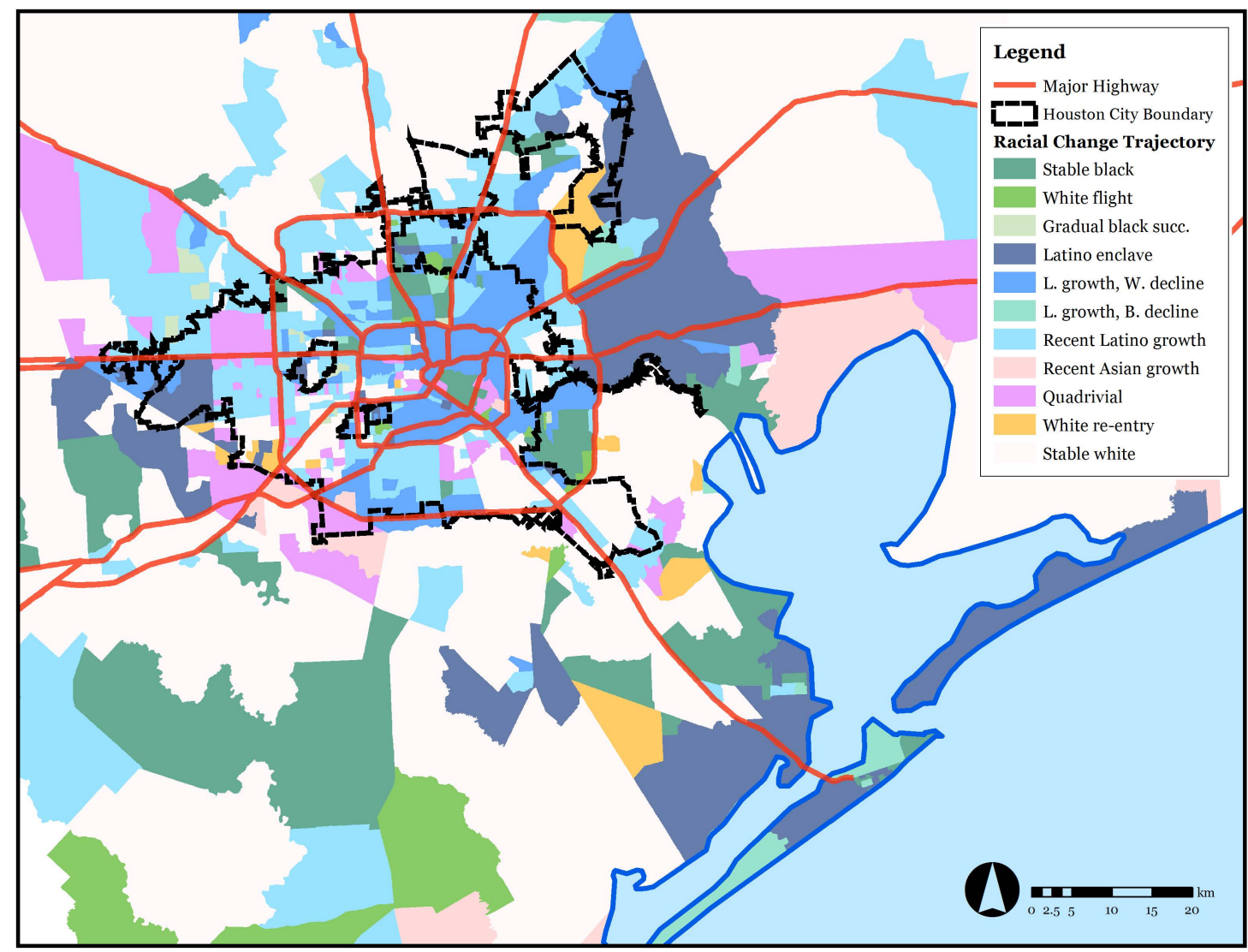

Figure 6: Map of neighborhood racial change trajectories from 1970-2010 in the Houston metropolitan area (map shows a detail of neighborhoods in and near Houston; a map of the complete CMSA is available upon request)

\section{Zone of Latino Segregation: Consolidating Enclaves and Suburban Dispersion}

Current Latino segregation came about through two processes. The first was the consolidation of traditional enclaves. As traditional enclaves (mapped in navy blue) continued to become increasingly Latino, the Latino population grew in nearby neighborhoods as part of the post-immigration reform growth of the Latino population during 1970s. This happened in both white and black neighborhoods (mapped in mid-tones of blue and blue-green, respectively), though the latter was largely confined to Los Angeles. The result was a consolidation and expansion of existing enclaves.

The second process was the diffusion of Latino growth into outlying areas of the city and surrounding suburbs. After a handful of suburban neighborhoods experienced post-immigration reform Latino succession in the 1970s and 1980s, the disperson of Latino growth accelerated in the 1990s (mapped in light blue). Some recent Latino growth happened close to the few suburban post-immigration reform 
Latino growth neighborhoods, but most were scattered to even farther reaches of metropolitan areas.

The extent of these two processes depended on the metropolitan area. Ethnic consolidation was most common in Los Angeles, likely reflecting the earlier entry of Latinos to the metropolitan area. In Houston, ethnic enclaves started consolidating about a decade later, corresponding to a wave of post-immigration reform migration to the city. Both metropolitan areas had large swaths of consolidated ethnic enclaves. New York and Chicago had a larger degree of dispersion, possibly as a result of the changing real estate economy that occurred when Latino immigration to those two cities accelerated in the 1990s. Existing enclaves may have had less time to consolidate, which might also explain why Latino enclaves in those two metropolitan areas were more vulnerable to gentrification and the associated white re-entry.

\section{Zone of Asian Segregation: Coastal Dispersion}

Higher proportions of neighborhoods in New York and Los Angeles belonged to the Asian growth trajectory than in Chicago and Houston, reflecting the higher level of Asian growth in those two metropolitan areas. Like recent Latino growth, Asian growth was spatially dispersed (mapped in rose). In New York, Asian growth occurred in a few small pockets in the outer boroughs, places like Sunset Park in Brooklyn and Whitestone in Queens, as well as in suburbs scattered throughout Long Island and North New Jersey. In Los Angeles, Asian growth neighborhoods were often outside of the city of Los Angeles, being more clustered in a few locations like San Gabriel and Cerritos. The few Houston neighborhoods identified as following the Asian growth trajectory were also scattered in suburban communities like Sugar Land to the west and Baytown to the east. In each of these three metropolitan areas, quadrivial neighborhoods surround Asian growth neighborhoods. This reflects both the expanding geography of Asian segregation and also the slower pace of Asian spatial expansion compared to the diffusion of black neighborhoods and consolidation of Latino enclaves.

\section{Zone of Increasing Integration: Growing Suburban Diversity}

Durable integration in the post-Civil Rights Movement era is largely a suburban phenomenon. Quadrivial neighborhoods (mapped in fuchsia) were more likely to be found in the suburbs than in the four central cities. Although most were relatively close to central cities, some quadrivial neighborhoods emerged in distant suburbs of all four cities in places like Bound Brook, New Jersey; Aliso Viejo, California; Naperville, Illinois; and Sugar Land, Texas. Minority footholds in stable white neighborhoods were typically suburban as well. In Los Angeles quadrivial neighborhoods were almost as common as stable white neighborhoods; in the other three metropolitan areas minority footholds were much more common.

The maps reveal that the other trajectory of durable integration, white re-entry into Latino neighborhoods (mapped in goldenrod), occurred in neighborhoods with convenient access to central business districts. In Chicago, white re-entry occurred in Wicker Park and Uptown, two neighborhoods with easy access to 'L.' lines. 
In New York, the neighborhoods on the Brooklyn side of the East River bridges followed the white re-entry trajectory as well as the suburban towns of Jersey City and Weehawken, which are located at the New Jersey terminals of the Holland and Lincoln Tunnels.

In summary, the geographic contours of segregation can be summarized as the concentric diffusion of the black ghetto, the initial expansion of Latino enclaves, and the recent suburban dispersion of Latino and Asian growth neighborhoods. The contours of durable integration are largely suburban except for the quarter of durably integrated neighborhoods that experienced white re-entry, which were in centrally located neighborhoods. We expect the suburban expansion of integration to continue as minorities have gained footholds in mostly white suburban neighborhoods.

\section{Robustness to the Number of Trajectories}

Warren et al. (2015) warn of overstating the certainty with which one asserts to have identified the correct number of classes from growth mixture models. We determined that the model contained 11 trajectories based on three factors: a substantial decline in the rate of BIC improvement, a statistically significant LMRLRT value, and a high entropy score. To investigate how our conclusions would change if we misestimated the correct number of trajectories, we also examined the 10- and 12-trajectory models.

The 10-trajectory model did not include the "gentrifying" trajectory of white re-entry into Latino enclaves. The other trajectories were substantively similar to those in the 11-trajectory model. Column 1 of Table 3 reports the percentage of neighborhoods classified in the same substantive trajectory in the 10-trajectory model as they were in the 11-trajectory model. For seven trajectories, at least 95 percent of neighborhoods were classified in the same trajectory across models. The lowest correspondence between models was for neighborhoods following the Latino enclave trajectory. Seventy-two percent of neighborhoods classified as Latino enclaves in the 11-trajectory model were classified as Latino enclaves in the 10-trajectory model. Since the gentrifying trajectory mimics the Latino enclave trajectory through the 1980s, we are not surprised that Latino enclaves would be the trajectory with which most gentrifying neighborhoods would be identified. Post-immigration reform succession and recent Latino succession were the other two trajectories with less than 95 percent correspondence, but even for these neighborhoods the correspondence was greater than 90 percent.

The 12-trajectory model included a trajectory of gradual integration between Latinos and Blacks. Column 2 of Table 3 reports the percentage of neighborhoods classified in the same substantive trajectory in the 12-trajectory model as they were in the 11-trajectory model. Five trajectories had greater than 95 percent correspondence between models. Two trajectories, white flight and post-immigration reform Latino succession from white neighborhoods had close to 85 percent correspondence. The least correspondence was found in the gradual black succession (72 percent) and recent Latino growth (69 percent). This suggests that some of the 
Table 3: Percentage of neighborhoods classified in 11-trajectory model with same classification in 10-trajectory and 12-trajectory models

\begin{tabular}{lcc} 
& \multicolumn{2}{c}{ Trajectories in model } \\
Trajectory & 10 & 12 \\
\hline Stable black & 98.2 & 99.0 \\
white flight & 99.0 & 85.3 \\
Gradual black succession & 98.4 & 71.7 \\
Latino enclave & 72.1 & 96.7 \\
Gradual Latino succession from white & 90.9 & 83.8 \\
Gradual Latino succession from black & 98.6 & 98.9 \\
Recent gradual Latino succession & 93.0 & 68.6 \\
Recent gradual Asian succession & 98.4 & 99.8 \\
Quadrivial integration & 99.5 & 97.0 \\
White re-entry & $\mathrm{N} / \mathrm{A}$ & 99.8 \\
Stable white & 99.5 & 98.6 \\
\hline
\end{tabular}

gradual succession of blacks and Latinos is occurring in the same neighborhoods, making integration among blacks and Latinos more likely.

Based on these results, we are confident that neither subtracting one class nor adding one substantially affect our main conclusions. Gradual succession and longterm racial change are consistent across all three models. That said, the multipleminority succession trajectory is a theoretically important trajectory that could be emerging and might be identified after adding data from the current decade.

\section{Gradual Succession and the Evolution of Racial Segrega- tion in Post-Civil Rights Movement Metropolitan Areas}

Our results demonstrate the high prevalence of slow but steady racial change in metropolitan neighborhoods during the post-Civil Rights Movement era. Our evidence supports Logan and Zhang's (2010) assessment of a "new polarization" occurring in U.S. metropolitan areas. We also uncover evidence, however, that their assessment (as well as many others) underestimates the risk of racial residential segregation in the post-Civil Rights Movement landscape.

We come to this conclusion by contributing a new method that clarifies how racial composition is changing in the largest metropolitan areas in the United States. This method not only allows us to examine the entire period following the Fair Housing Act, but also to distinguish neighborhoods that underwent gradual racial succession from those that experienced durable racial integration. We also improve on the previous literature by studying where neighborhoods are expected to follow each of the trajectories we identified. Our results provide a clear depiction of the temporal and geographic patterns of neighborhood change creating this "new polarization."

Table 4 summarizes our findings. The first column after the name reports the percentage of neighborhoods that follow the trajectory. The second reports the class of racial change the trajectory follows. The third and fourth columns report when 
change starts to occur and the the type of change that occurs. The final column summarizes where the trajectory occurred.

The zone of black segregation (summarized in the first three rows of Table 4) has come about as black growth diffused from traditional ghettos to surrounding neighborhoods. This happened quickly at first as whites fled neighborhoods adjacent to ghettos in the 1970s. A more gradual succession started during the 1980s in the neighborhoods surrounding where white flight had happened in the 1970s. The result is large swaths of near-complete segregation of blacks from whites. This pattern of change helps explain why blacks remained "stuck in place" (Sharkey 2013) in post-Civil Rights Movement society.

The zone of Latino segregation emerged in two stages (summarized in rows four through seven of Table 4). In the first, Latino growth was clustered in and around existing Latino enclaves. In the second, Latino growth became much more geographically dispersed throughout the metropolitan areas. As a result, segregated (or segregating) Latino neighborhoods are far less geographically clustered than segregated black neighborhoods. Instead, Latino segregation looks like a checkerboard covering these metropolitan areas-especially New York and Chicago, which experienced slower and later Latino growth than either Los Angeles or Houston.

The dual pattern of Latino growth helps to explain Farrell and Lee's (2011) paradoxical finding that Latinos are the racial group most likely to experience increasing isolation and the most likely to initiate neighborhood racial diversity. Farrell and Lee's study of change in the 1990s would have captured both the increasing isolation coming about in consolidating enclaves and the suburban dispersion of Latino growth that picked up in the 1990s. Our study provides additional details to help explain how these patterns came about in post-Civil Rights metropolitan areas.

The zone of Asian segregation (summarized in row eight of Table 4) also reflected a checkerboard of dispersed Asian growth in outlying city and suburban neighborhoods. These neighborhoods were most likely to emerge in the two metropolitan areas that experienced sustained Asian growth: New York and Los Angeles.

Durable integration emerged in two different ways in the 1990s: through quadrivial integration and through white re-entry into Latino neighborhoods. Of these two, quadrivial integration (summarized in the ninth row of Table 4) was more common. Quadrivial neighborhoods were located on the peripheries of cities or in the suburbs. They reveal the misconception of racially homogenous suburban communities. Declining suburban homogeneity will likely continue as minorities have gained a foothold in the suburban stable white communities in all four metropolitan areas (summarized in the last row of Table 4). White re-entry happened in gentrifying neighborhoods with easy access to the Central Business District (summarized in the second-to-last row of Table 4). The racial change appears slow enough that Latinos will likely be considered present for a considerable amount of time. 


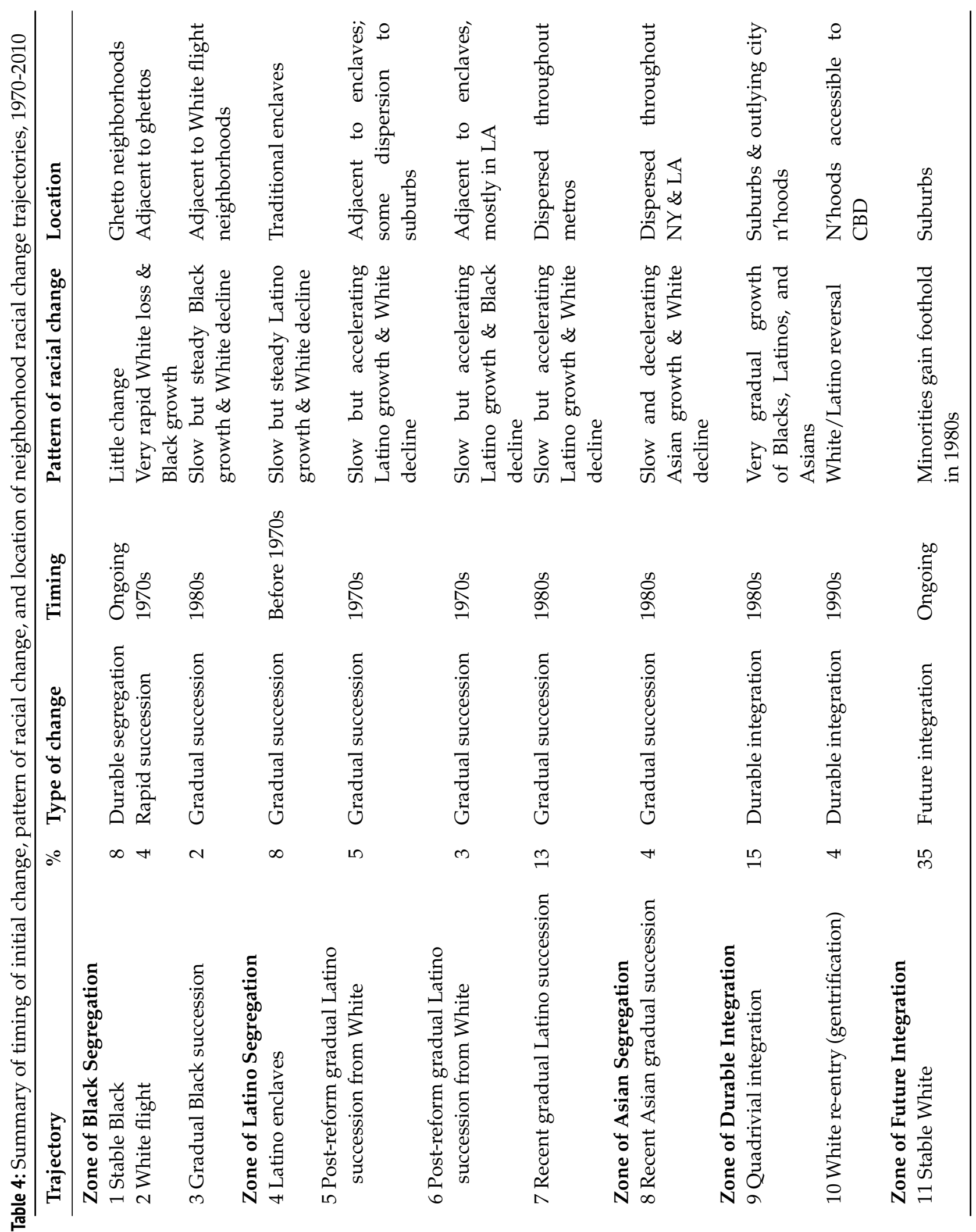




\section{Limitations}

Although our approach improves the study of neighborhood racial change, we recognize its limitations. A major limitation of growth mixture models is that they rely on the analyst to interpret the correct number of classes. Growth mixture models are sensitive to deviations from the assumed distribution, potentially leading to a misspecification of unique trajectories (Bauer and Curran 2003). Using proportions, even after transformation, might lead to problems estimating the correct number of trajectories. In addition, the use of the arcsine square-root transformation introduces nonlinear terms that could account for the significant quadratic and cubic terms.

To address this problem, we provide a supplement reporting the results of an analysis in which we estimated the model using untransformed proportions as the outcome (the results of which can be found in Figure S1 of the supplement). In this estimation, the quadratic and cubic estimates were statistically distinguishable from the null for the trajectories that we would expect (e.g., white flight). We are therefore confident that the nonlinear results do not reflect an artifact of the arcsine square-root transformation. The trajectories identified by estimating the model with untransformed proportions as the outcome differed slightly from those identified by estimating the model using the transformed proportions. We did not find evidence of the white re-entry or post-reform Latino gradual succession trajectories and instead found a Latino/black growth trajectory (shown in Figure S1f) and a trajectory of increased Latino/Asian integration (shown in Figure S1j). Because these models include out-of-bounds estimates (i.e., proportions greater than one), we remain more confident in the models based on the transformation. Ultimately, however, the ideal solution would be to use multinomial logistic regression models, a solution that remains infeasible at present because of the computational demands required to estimate such models.

Problems introduced by the transformation aside, some evidence suggests that even when using the correct specification, growth mixture models can underestimate the correct number of classes (Warren et al. 2015). Our robustness check mitigates some concerns related to correctly identifying the true number of latent trajectories. The last two trajectories identified when estimating the model were both novel trajectories that emerged in recent decades (gentrification and multiple minority integration). It would make sense that more recent trajectories would be the most difficult to identify because racial changes could more easily be conflated with a more established trajectory. It is possible that with another decade of data, these trajectories might become clearer. Fortunately, growth mixture modelsunlike transition matrices - can easily accommodate more data in a longitudinal series.

Substantively, our study is limited by only studying the metropolitan areas of the four largest cities in the United States. This limits the comparability of our study to studies with different samples. We feel justified in focusing on a small number of well studied cities because it afforded us the opportunity to examine geographic patterns associated with neighborhood racial change trajectories. We also note that our method identified common racial change trajectories, not meaningful trajectories. As a result, we may miss substantively important but relatively infrequent patterns of racial change, such as white gentrification of black neighborhoods (Hyra 2008). 
Multiple studies using multiple methods is, in our estimation, the best solution to address this problem.

\section{Implications of Fragmented Trajectories of Racial Integration in the Twenty-First Century}

Though mindful of these limitations, our study suggests important implications for understanding racial stratification in the twenty-first century. We find reason for continued concern about racial segregation in the post-Civil Rights Movement United States. Our conclusion contradicts other accounts of recent years. For example, Glaeser and Vigdor (2012:ii) write that "[a]ll-white neighborhoods are effectively extinct" and use this evidence to argue that the country has experienced the "end of segregation." Even Logan and Zhang $(2010 ; 2011)$ are relatively sanguine about the prospects of integration. Our assessment differs from those studies because we look not only at the presence of racial groups but the degree to which nominally integrated neighborhoods are integrated. We find that many are not: six of eleven trajectories, which occur in thirty-five percent of neighborhoods, experienced gradual racial succession. Previous studies missed this process and, thus the cause for concern.

Our results suggest that the processes creating segregation have changed in the decades since the Civil Rights Movement. Although white flight was prevalent in the years immediately following Civil Rights legislation, we find that it ended during the 1970s. After that white avoidance of minority neighborhoods appears to cause segregation. The shift from active white flight to passive white avoidance marks a significant change in the process of segregation.

Shifting processes require shifts in policies that promote racial integration. Policies that exclusively ensure that minorities can enter all-white neighborhoods will produce only modest gains toward integration, especially since many minorities have already gained footholds in majority-white neighborhoods. Policies must also encourage whites to consider living in integrated neighborhoods, particularly neighborhoods where the share of blacks is growing.

The unwillingness of whites (and Asians and, to a lesser degree, Latinos) to consider living in black neighborhoods is currently undermining housing markets in black neighborhoods. Therefore it is increasingly important to find policies that encourage whites to seek out integrated neighborhoods. Public infrastructure development and incentives for private investment could help stabilize black neighborhoods and could be justified as part of reparations for mid-century housing discrimination (Coates 2014). Policies must be ongoing because, as our analysis shows, not all segregation can be blamed on past discriminatory policies.

The dispersion of Latino and Asian communities will present new challenges to incoming migrants. Suburban local governments might not be as prepared to receive influxes of immigrants as central cities. For individuals, the process of assimilation might evolve as a result of being scattered in geographically dispersed enclaves, rather than concentrated in a few urban neighborhoods. Recent Latino and Asian growth neighborhoods might be worthwhile places to implement integration-promoting policies. Their distance from traditional Latino enclaves 
might help attract non-Latino residents otherwise hesitant to move to Latino neighborhoods based on their perceptions of traditional enclaves. The suburban location of many quadrivial neighborhoods provides evidence that these attempts could be successful.

On a more optimistic note, it does appear that many neighborhoods are durably integrated. These are neighborhoods where the racial changes end up reflecting the changing racial composition of the U.S. population. Even where durable integration does not yet exist, as is the case in stable white neighborhoods, minorities have gained footholds from which to make it happen in the future. The majority of durably integrated neighborhoods are in suburban communities, and the suburban quadrivial neighborhoods are more racially integrated than centrally located gentrifying neighborhoods. Programs and policies should support this integration by affirmatively marketing diverse neighborhoods and adjust perceptions that suburbs lack diversity.

The emergence of gradual succession requires new research as well. The longer it takes for racial changes to occur, the more likely it is that births and deaths will affect the composition of neighborhoods. The age and life-cycle dependent nature of residential moves and of births and deaths create the potential for neighborhoods to experience age-related racial succession (e.g., Finney 2013). Failing to examine births and deaths cause us to underestimate the possibility of gradual succession, but it also fails to consider how socially integrated racial groups are when living in the same neighborhood. Examining how long-term neighborhood racial change trajectories intersect the life courses of residents might illuminate why microsegregation comes about even in racially integrated neighborhoods.

Saul Alinsky is credited as saying that integration is the "time between when the first black moves in and last white moves out." For many neighborhoods in and around America's largest cities, we find that the time between those two events has become longer during the post-Civil Rights era; but, gradual succession ultimately ends in segregation. By the same token, other neighborhoods appear to maintain durable integration and thus prove Alinsky wrong. Quadrivial neighborhoods not only have all four groups present, they also appear to be on pace to maintain all four groups well into the future. The fragmentation of nominally integrated neighborhoods into these different trajectories defines post-Civil Rights Movement racial change. As a result, explaining how both gradual succession and durable integration have come about will be key to understanding how the the new polarization of U.S. metropolitan areas has evolved, and will continue to evolve in the twenty-first century.

\section{Notes}

1 Two notes on terminology throughout the paper are in order. First, we refer to "racial" integration, segregation, neighborhood change, etc. Besides the awkward constructions required to constantly repeat "racial and ethnic," Latinos are increasingly considered a racial rather than ethnic group. Second, this article focuses on residential segregation, not other potential arenas of segregation such as schools or workplaces. 
2 In our analysis of the results (e.g., Figure 2) we transformed the coefficients to proportions by taking the sine of the growth factor coefficient, $\beta_{f r}$, estimated for growth factor $f$ of race $r$, squaring the result, and retaining the sign of the coefficient; i.e., $p_{f r}^{*}=$ $\sin \left(\beta_{f r}\right)^{2} \times \operatorname{sign}\left(\beta_{f r}\right)$.

3 Figure 2 is based on the transformed parameters estimated from the growth mixture model. Because the percentage of whites was not modeled directly in order to avoid multicollinearity, the percentage of whites was determined by subtracting the sum of black, Latino, and Asian percentages from 100.

4 There were riots in the Harlem and Bedford-Stuyvesant neighborhoods of New York in 1964; in Watts, Los Angeles in 1965; and in the Austin, Lawndale, and Woodlawn neighborhoods of Chicago following the assassination of the Rev. Dr. Martin Luther King, Jr. in 1968.

\section{References}

Bader, Michael D. 2009. Spatial and Temporal Contexts of Neighborhood Environments in Metropolitan Chicago. Unpublished dissertation, University of Michigan, Ann Arbor, Michigan.

Bauer, Daniel J. and Patrick J. Curran. 2003. “Distributional Assumptions of Growth Mixture Models: Implications for Overextraction of Latent Trajectory Classes." Psychological Methods 8:338-363. http://dx.doi.org/10.1037/1082-989x.8.3.338.

Charles, Camille Zubrinsky. 2000. “Neighborhood Racial-Composition Preferences: Evidence from a Multiethnic Metropolis." Social Problems 47:379-407. http://dx.doi.org/10. 2307/3097236.

Clark, William A. V. 1993. "Neighborhood Transitions in Multiethnic/Racial Contexts." Journal of Urban Affairs 15:161-172. http://dx.doi.org/10.1111/j.1467-9906.1993. tb00308.x.

Coates, Ta-Nehisi. 2014. "The Case for Reparations." The Atlantic Monthly 313:54-71. Obtained June 27, 2014 from http: //www. theatlantic.com/features/archive/2014/05/ the-case-for-reparations/361631.

Crowder, Kyle, Matthew Hall, and Stewart E. Tolnay. 2011. “Neighborhood Immigration and Native Out-Migration." American Sociological Review 76:25-47. http://dx.doi .org/ 10.1177/0003122410396197.

Denton, Nancy A. and Douglas S. Massey. 1991. "Patterns of Neighborhood Transition in a Multiethnic World: U.S. Metropolitan Areas, 1970-1980." Demography 28:41-63. http://dx.doi.org/10.2307/2061335.

Drake, St. Clair and Horace R. Cayton. [1945]1993. Black Metropolis: A Study of Negro Life in a Northern City. Chicago, Ill: University Of Chicago Press.

DuBois, W. E. B. [1899]1996. The Philadelphia Negro: A Social Study. Philadelphia: University of Pennsylvania Press.

Duncan, Otis Dudley and Beverly Duncan. 1957. The Negro Population of Chicago; a Study of Residential Succession. Chicago: University of Chicago Press.

Ellen, Ingrid Gould. 2000. Sharing America's Neighborhoods: The Prospects for Stable Racial Integration. Cambridge, Mass.: Harvard University Press. 
Farley, Reynolds. 2011. "The Waning of American Apartheid?" Contexts 10:36-43. http: //dx.doi.org/10.1177/1536504211418452.

Farrell, Chad R. and Barrett A. Lee. 2011. "Racial diversity and change in metropolitan neighborhoods." Social Science Research 40:1108-1123. http://dx.doi.org/10.1016/j . ssresearch.2011.04.003.

Finney, Nissa. 2013. "How Ethnic Mix Changes: Typologising Neighbourhood Population Dynamics of Ethnic Groups." In Understanding Neighbourhood Dynamics, edited by Maarten van Ham, David Manley, Nick Bailey, Ludi Simpson, and Duncan Maclennan, pp. 203-224. Dordrecht: Springer Netherlands.

Friedman, Samantha. 2008. "Do declines in residential segregation mean stable neighborhood racial integration in metropolitan America? A research note." Social Science Research 37:920933. http://dx.doi.org/10.1016/j.ssresearch.2007.06.010.

Glaeser, Edward and Jacob Vigdor. 2012. “The End of the Segregated Century: Racial Separation in America's Neighborhoods, 1890-2010." Civic Report 66, Manhattan Institute Center for State and Local Leadership, New York.

Hyra, Derek S. 2008. The New Urban Renewal: The Economic Transformation of Harlem and Bronzeville. Chicago: University Of Chicago Press.

Iceland, John. 2004. "Beyond Black and White: Metropolitan residential segregation in multi-ethnic America." Social Science Research 33:248-271. http://dx.doi .org/10.1016/ S0049-089X (03) 00056-5.

Jackson, Kenneth T. 1985. Crabgrass Frontier: The Suburbanization of America. New York: Oxford University Press.

Jaeger, T. Florian. 2008. “Categorical data analysis: Away from ANOVAs (transformation or not) and towards logit mixed models." Journal of Memory and Language 59:434-446. http://dx.doi.org/10.1016/j.jml.2007.11.007.

Krysan, Maria and Michael Bader. 2007. "Perceiving the Metropolis: Seeing the City Through a Prism of Race." Social Forces 86:699-733. http://dx.doi .org/10.1093/sf/86.2.699.

Krysan, Maria and Michael D. M. Bader. 2009. "Racial Blind Spots: Black-White-Latino Differences in Community Knowledge." Social Problems 56:677-701. http://dx.doi .org/ 10.1525/sp.2009.56.4.677.

Krysan, Maria and Reynolds Farley. 2002. "The Residential Preferences of Blacks: Do They Explain Persistent Segregation?" Social Forces 80:937-980. http://dx.doi.org/10.1353/ sof .2002.0011.

Lewis, Valerie A., Michael O. Emerson, and Stephen L. Klineberg. 2011. “Who We'll Live With: Neighborhood Racial Composition Preferences of Whites, Blacks and Latinos." Social Forces 89:1385-1407. http://dx.doi.org/10.1093/sf/89.4.1385.

Logan, John R., Zengwang Xu, and Brian J. Stults. 2014. “Interpolating U.S. Decennial Census Tract Data from as Early as 1970 to 2010: A Longitudinal Tract Database." The Professional Geographer 66:412-420. http://dx.doi.org/10.1080/00330124.2014.905156.

Logan, John R. and Charles Zhang. 2010. "Global Neighborhoods: New Pathways to Diversity and Separation." American Journal of Sociology 115:1069-1109. 
Logan, John R. and Wenquan Zhang. 2011. “Global Neighborhoods: New Evidence from Census 2010." Technical report, US2010 Project.

Maly, Michael T. 2005. Beyond segregation: multiracial and multiethnic neighborhoods in the United States. Philadelphia: Temple University Press.

Massey, Douglas S. and Nancy A. Denton. 1993. American Apartheid: Segregation and the Making of the Underclass. Cambridge, Mass.: Harvard University Press.

Massey, Douglas S. and Kristin E. Espinosa. 1997. "What's Driving Mexico-U.S. Migration? A Theoretical, Empirical, and Policy Analysis." The American Journal of Sociology 102:939-999. http://dx.doi.org/10.1086/231037.

Molotch, Harvey. 1969. "Racial Change in a Stable Community." The American Journal of Sociology 75:226-238. http://dx. doi .org/10.1086/224768.

Muthén, Bengt and Kerby Shedden. 1999. "Finite Mixture Modeling with Mixture Outcomes Using the EM Algorithm." Biometrics 55:463-469. http://dx. doi .org/10.1111/j . $0006-341 X .1999 .00463 . x$.

Palloni, Alberto, Douglas S. Massey, Miguel Ceballos, Kristin Espinosa, and Michael Spittel. 2001. "Social Capital and International Migration: A Test Using Information on Family Networks." American Journal of Sociology 106:1262-1298. http://dx.doi .org/10.1086/ 320817.

Petras, Hanno and Katherine Masyn. 2010. "General Growth Mixture Analysis with Antecedents and Consequences of Change." In Handbook of Quantitative Criminology, edited by Alex R. Piquero and David Weisburd, pp. 69-100. Springer New York. http://dx.doi.org/10.1007/978-0-387-77650-7_5.

Sassen, Saskia. 1991. The global city: New York, London, Tokyo. Princeton University Press.

Sharkey, Patrick. 2013. Stuck in Place: Urban Neighborhoods and the End of Progress toward Racial Equality. University Of Chicago Press, 1 edition edition.

Stepler, Renee and Anna Brown. 2015. "Statistical Portrait of Hispanics in the United States, 1980 âĂŞ 2013." Technical report, Pew Research Center Hispanic Trends Project.

Sugrue, Thomas J. 1996. The origins of the urban crisis : race and inequality in postwar Detroit. Princeton, NJ: Princeton University Press. Book, Whole.

Taeuber, Karl E and Alma F Taeuber. 1965. Negroes in Cities; Residential Segregation and Neighborhood Change. Chicago: Aldine Pub. Co.

Tatian, Peter A. 2003. "Neighborhood Change Database (NCDB) 1970-2000 Tract Data: Data User's Guide Long Form Release." Technical report, The Urban Institute, Washington, D.C.

Timberlake, Jeffrey M. and John Iceland. 2007. "Change in Racial and Ethnic Residential Inequality in American Cities, 1970-2000." City E Community 6:335-365. http://dx. doi . org/10.1111/j.1540-6040.2007.00231.x.

Warren, John Robert, Liying Luo, Andrew Halpern-Manners, James M. Raymo, and Alberto Palloni. 2015. "Do Different Methods for Modeling Age-Graded Trajectories Yield Consistent and Valid Results?" American Journal of Sociology 120:1809-1856. 
Wyly, Elvin K. and Daniel J. Hammel. 1999. “Islands of Decay in Seas of Renewal: Housing Policy and the Resurgence of Gentrification." Housing Policy Debate 10:711-771.

Acknowledgements: An earlier version of this paper was presented at the 2013 Annual Meeting of the Population Association of America in New Orleans, at the Population Research Institute of the Pennsylvania State University, and at the Maryland Population Research Center at the University of Maryland. The article benefited greatly from the comments received at those venues as well as those generously offered by Jennifer Ailshire, Maria Krysan, jimi adams, Nina Yamanis, Randa Serhan, Derek Hyra, and Kathy Neckerman. The authors acknowledge the financial support of the Robert Wood Johnson Foundation Health \& Society Scholars Program. The authors are solely responsible for any errors or omissions in this paper.

Michael D. M. Bader: Department of Sociology, American University. E-mail: bader@american.edu.

Siri Warkentien: Department of Sociology, Johns Hopkins University. 